\title{
Comparison of image analysis and flow cytometric determination of cellular DNA content
}

\author{
C Cope, D Rowe, L Delbridge, J Philips, M Friedlander
}

\begin{abstract}
$A$ good correlation $(r=0.94)$ was obtained between the DNA indices (DI) using flow cytometry and image analysis of nuclei cytospins extracted from paraffin wax embedded tumour sections. Some of the limitations and problems associated with image analysis which came to light included an unacceptably high coefficient of variation (CV) and a "left-shift" in the DI in most DNA histograms obtained when using image analysis of $5 \mu \mathrm{m}$ sections. In contrast, the DNA histograms generated using image analysis of cytospun nuclei from paraffin wax blocks were of good quality and similar to those obtained using flow cytometry. Variability in Feulgen staining was common and an important source of error despite rigorous control of the staining technique. This could be ovecome by using internal controls such as fibroblasts rather than external controls (rat hepatocytes) to determine the diploid DI with image analysis.

$A$ thorough understanding and appreciation of the methodological problems associated with image analysis and flow cytometric determination of DNA content is required before these methods find widespread clinical application.
\end{abstract}

Aneuploidy is recognised as a common feature of malignancy and there is growing evidence to indicate that ploidy is of prognostic importance in various tumour types. Flow cytometry has emerged as a powerful tool well suited for the rapid analysis of cellular DNA content and proliferative activity. Improvements in cell preparative and staining techniques, as well as the development of a new method to extract nuclei from paraffin wax embedded tumour blocks, have enabled a large number of retrospective studies to be carried out into the prognostic importance of tumour ploidy. ${ }^{1}$ The advantages and relative merits of the technique have been reported as have the practical problems and limitations associated with flow cytometric analysis. Many of these problems have been largely overcome as a result of technical and methodological improvements. A major problem of flow cytometric analysis of DNA content, however, is that it does not permit discrimination between "normal" host cells and tumour cells that have a diploid DNA content. The presence of a minority population of aneuploid tumour cells may also be masked when there is a preponderance of non-malignant cells in the sample, leading to potential errors in interpretation of DNA histograms obtained using flow cytometry. ${ }^{2}$ This has provoked increased interest in assessing DNA content using image analysis of Feulgen stained nuclei as direct visualisation of the tumour sample is possible and malignant cells may be preferentially selected for analysis thus giving greater specificity. The aim of this study was to determine whether DNA content could be determined accurately using image analysis and to correlate the findings with those of flow cytometric analysis.

\section{Methods}

Nuclear DNA content of 27 phaeochromocytomas was measured using image analysis of $5 \mu \mathrm{m}$ sections and cytospin preparations of nuclei extracted from $30 \mu \mathrm{m}$ sections of paraffin wax embedded tissue blocks. Cytospins were also prepared from tissue blocks of 46 ovarian carcinomas that had been analysed previously using flow cytometry, ${ }^{3}$ and the DNA content was measured by image analysis.

Slides stained with haematoxylin and eosin from the phaeochromocytomas were reviewed and representative sections with minimal haemorrhage or necrosis were chosen. Three $5 \mu \mathrm{m}$ and two $30 \mu \mathrm{m}$ sections were then cut contiguously from the blocks corresponding to the best sections. One of the $5 \mu \mathrm{m}$ sections was stained with haematoxylin and eosin to review the histological analysis.

One $5 \mu \mathrm{m}$ and two $30 \mu \mathrm{m}$ sections were cut from the same tissue blocks of the ovarian carcinomas that had been used for flow cytometry: the $5 \mu \mathrm{m}$ section was used as a record of the tissue analysed.

The cytospins were prepared from nuclear suspensions obtained from the $30 \mu \mathrm{m}$ sections using the method of Hedley et al. ${ }^{1}$ Briefly, $30 \mu \mathrm{m}$ sections were placed in $10 \mathrm{ml}$ glass centrifuge tubes and dewaxed using two changes of Histoclear $(3 \mathrm{ml}$ for 10 minutes at room temperature, then centrifuged for 10 minutes at $2000 \mathrm{rpm}$ ). Rehydration was then carried out by sequential immersion in $100 \%$, $95 \%, 70 \%$, and $50 \%$ ethanol. The sections were then washed once in distilled water and once in $0.9 \%$ sodium chloride, minced with scissors while under water, and resuspended in $1 \mathrm{ml} 0.5 \%$ pepsin in $0.9 \%$ sodium chloride adjusted to $\mathrm{pH} 1.5$ with $2 \mathrm{~N}$ hydrochloric acid. 
Figure 1 Scattergrams of DIs comparing values obtained using image analysis (VIA) and flow cytometry ( $F C M$ ) of ovarian tumours. Diploid DIs were obtained using rat hepatocytes as diploid controls (left) and

fibroblasts as an internal control (right). The two outliers in the right hand figure represent borderline ovarian tumours. At clinical follow up both patients were alive with no evidence of tumour recurrence.

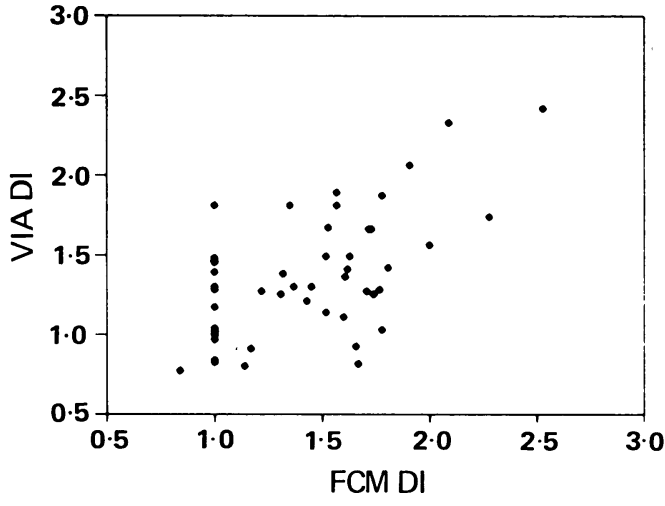

The suspension was then incubated for 30 minutes at $37^{\circ} \mathrm{C}$ in a water bath, with the suspensions vortexed every five minutes, after which the reaction was stopped by washing the nuclei in $3 \mathrm{ml}$ HEPES buffered RPMI (pH 7.1). The suspension was then filtered using a $53 \mu \mathrm{m}$ mesh and spun at $1000 \mathrm{rpm}$ for 10 minutes. The resulting nuclei were resuspended in $0.5 \mathrm{ml} \mathrm{RPMI}$ medium, and a $20 \mu \mathrm{l}$ aliquot was removed to determine the nuclear yield (20 $\mu \mathrm{l}$ of nuclear suspension mixed with $20 \mu$ l of trypan blue). The cells were then centrifuged on to slides using the Shandon Southern cytospin centrifuge $(750 \mathrm{rpm}$ for five minutes). These were fixed in $10 \%$ neutral formalin.

The cytospins and one $5 \mu \mathrm{m}$ section from each phaeochromocytoma was then stained with the Feulgen stain, together with cells provided by Cell Analysis Systems, Inc, Elmhurst, Illinois, USA (CAS) (rat hepatocytes) and $5 \mu \mathrm{m}$ sections of tonsillar tissue for con-

Figure 2 DNA histograms of a multiploid ovarian tumour showing the close correlation between flow cytometry (above) and image analysis (below).
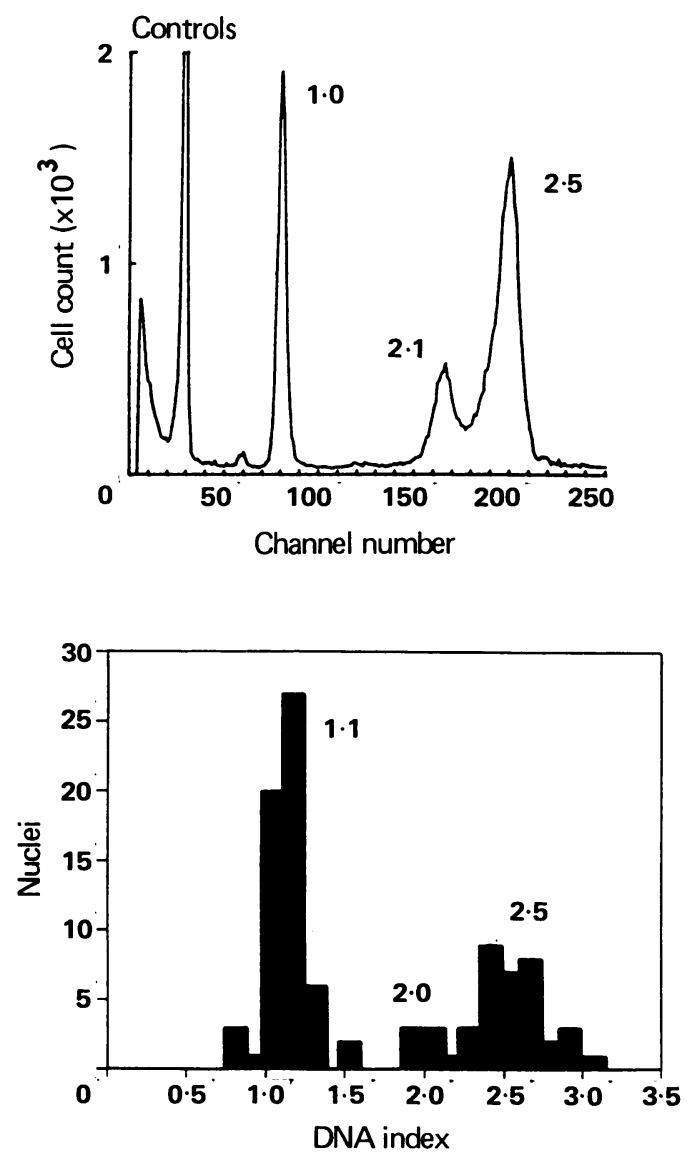

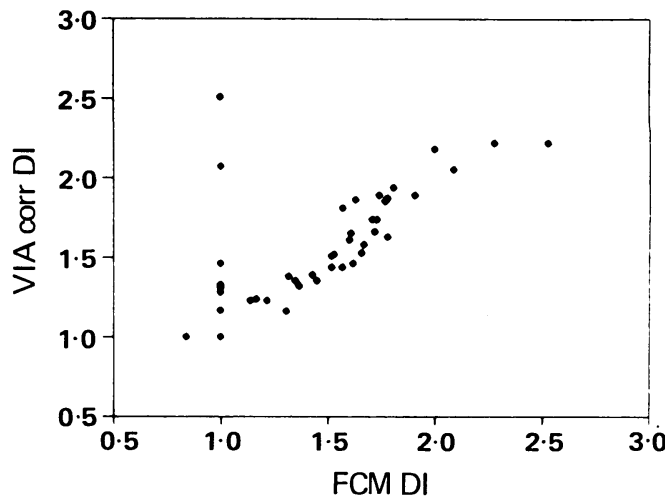

trols. The Feulgen staining was carried out for one hour, with an eight minute period of hydrolysis at $60^{\circ} \mathrm{C}$ using $2 \cdot 7 \mathrm{M}$ hydrochloric acid.

Both the cytospins and the $5 \mu \mathrm{m}$ sections were examined blind using the CAS-100/ QDA system, and scanning at a wavelength of $560 \mu \mathrm{m} .{ }^{4}$ The system was calibrated using rat hepatocytes provided by CAS. Cells which appeared complete and were not overlapped by others were studied under $\times 40$ power. At least 200 cells from each tumour were examined in the $5 \mu \mathrm{m}$ sections, and $100-200$ in the cytospin preparations, with cells taken from multiple areas of the section or slide. The DNA histogram was then generated by the QDA program, and the DI of each histogram was calculated by the computer.

The coefficients of variation of the DI modal peaks of the $5 \mu \mathrm{m}$ sections and cytospins of the phaeochromocytomas were compared using the $t$-test, with percentage points for a two-tailed distribution.

\section{Results}

Several methodological problems were apparent early in the study. These included the difficulty of obtaining good quality DNA histograms on $5 \mu \mathrm{m}$ sections and the recognition that calibration using rat hepatocytes (provided by CAS on slides) was inaccurate in terms of determining the DI in paraffin wax embedded tissue. The diploid DI was therefore determined by measuring the DNA content of $20-50$ fibroblasts in the tumour specimen and then corrected using this value.

There was a good correlation between the DIs of ovarian carcinomas obtained using flow cytometry and image analysis of cytospin nuclei extracted from paraffin blocks (figs 1 and 2). The problem with $5 \mu \mathrm{m}$ sections was not confined to ovarian carcinoma but was also seen in phaeochromocytomas where the $\mathrm{CV}$ of the cytospin preparation $(5.9 \%)$ was significantly less than the corresponding $5 \mu \mathrm{m}$ section $(13.6 \%)(p=0.001)$. This made it very difficult to assess accurately DNA content in $5 \mu \mathrm{m}$ paraffin wax embedded tissue sections (fig 3). Twelve tumours were classified the same using both methods (seven diploid and five aneuploid). Fifteen tumours, however, were classified differently by the two methods, and these results are compared in the table. In all but three of the tumours the 
Figure 3 The top histogram shows the problem of interpreting some histograms obtained resulting from high $C V$ s. The cytospin preparation resolves this problem, showing an aneuploid tumour with a DI of $1 \cdot 17$, with a high proliferative component in the $G 2+M$ peak at $a D I$ of $2 \cdot 31$, and also some octaploid cells with $a$ DI of $4 \cdot 8$. using $5 \mu \mathrm{m}$ sections
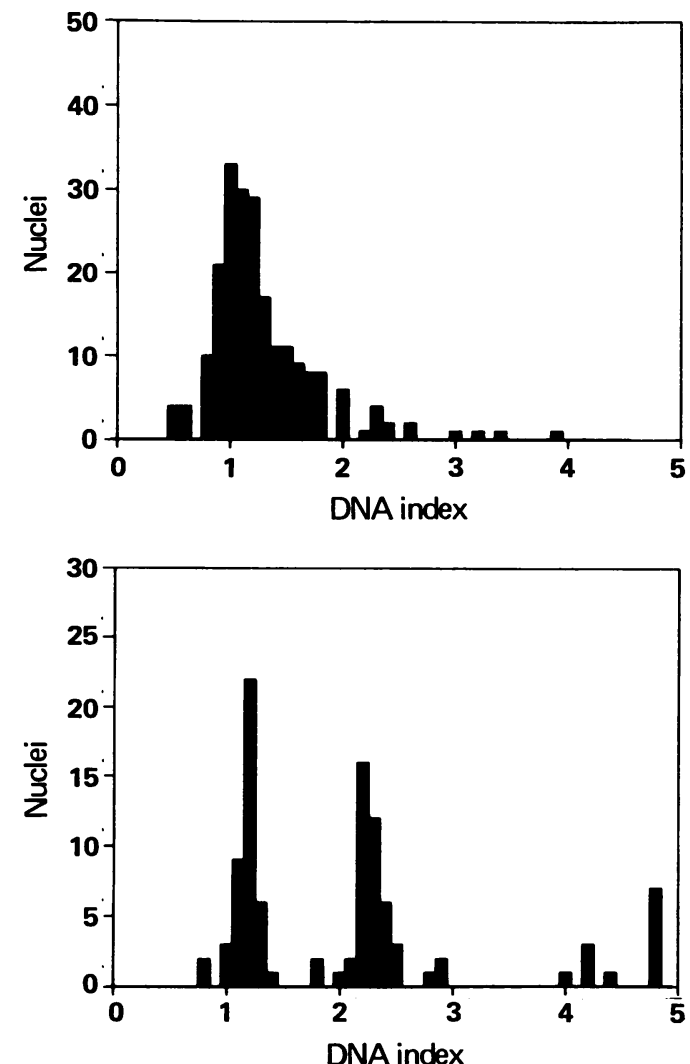

Differences in DNA pattern classification

\begin{tabular}{llll}
\hline & \multicolumn{2}{l}{ Cytospin } & \\
\cline { 2 - 4 } Slide & Diploid & Aneuploid & Tetraploid \\
\hline Diploid & & 3 & 3 \\
Aneuploid & 1 & & 8 \\
\hline
\end{tabular}

Figure 4 DNA histograms of a phaeochomocytoma, showing how the "leftshift" resulted in the classification of the tumour as aneuploid using $5 \mu \mathrm{m}$ sections (above), but as tetraploid using the cytospin preparation (below).
DI was higher in the cytospin preparation than in the $5 \mu \mathrm{m}$ section, the mean difference being 0.22 arbitrary units. This "left-shift" in the $5 \mu \mathrm{m}$ sections resulted in the classification of eight tumours, which were tetraploid in the cytospin preparation, as aneuploid in the $5 \mu \mathrm{m}$ section. An example of this "left-shift" is shown in fig 4 . The three tumours that were classified as diploid on $5 \mu \mathrm{m}$ sections but aneuploid on cytospin all had DIs close to $1 \cdot 2$, and these peaks were presumably masked in the diploid peak due to the high CVs in the $5 \mu \mathrm{m}$ sections.

\section{Discussion}

Cellular DNA content is of prognostic importance in a wide range of tumours including breast, colorectal, non-small cell lung cancer, ovarian and endometrial cancer, thyroid carcinoma, melanoma, and phaeochromocytoma..$^{5-12}$ Although there have been some conflicting results as to the prognostic importance of tumour ploidy, it seems certain that it will have clinical application in several tumour types. A thorough understanding and appreciation of the methodological and technical constraints associated with the measurement of cellular DNA content by flow cytometry or image analysis is essential to interpret the results of different studies. The aim of the current study was to compare image analysis and flow cytometric determination of DNA content and to assess the potential advantages and disadvantages of image analysis.

Most retrospective studies of the prognostic importance of DNA content have used flow cytometry, as it is regarded by many as the "gold standard," because of the statistical accuracy resulting from the large number of cells analysed..$^{13}$ It also allows cell cycle analysis to be performed, which is not possible with the analysis of small number of cells, but it does not permit visualisation of the cells analysed, thus possibly introducing errors if the sample contains relatively few tumour cells, with aneuploidy being related to the percentage of tumour cells in the sample. ${ }^{2}$

It is thus essential to assess accurately the content of the sample used in the preparation of the cells for flow cytometry. This can either be done histologically (by assessing adjacent sections to those used in the preparation of the cell suspension) or cytologically (assessing an aliquot of the cell suspension used for flow cytometry). This still does not permit the distinction between diploid tumour cells and other diploid cells in the sample, such as stromal and inflammatory cells.

Image analysis of thin $(4-5 \mu \mathrm{m})$ sections permits direct visualisation of the cells analysed, with simltaneous measurement of other morphological information, which is not possible using flow cytometry. It suffers, however, from the problem that most of the nuclei are not contained completely within the section. The inaccuracy of the measurement of DNA content increases with nuclear size, as the larger the nucleus is, the smaller the proportion 
of the nucleus which is measured, and thus the distribution of DNA values around the modal value becomes skewed to the left. This is especially important in the study of tumours such as phaeochromocytomas because of their pleomorphic nature, with some cells being well over $20 \mu \mathrm{m}$ in diameter. ${ }^{14-16}$

The use of the cytospin preparation overcomes this limitation of image analysis, and also permits the measurement of the DNA content of morphologically identified whole cells. ${ }^{17} \mathrm{~A}$ further advantage over flow cytometry is that damaged nuclei and other debris can be ignored, thus reducing "background noise" and often making it easier to determine the DI using image analysis rather than with flow cytometry. ${ }^{18}$

This study has shown that the cytospin technique correlates well with flow cytometry, with $r=0.94$. This agrees with the findings of previous studies, which show a very high correlation, with $\mathrm{r}>0.95 .^{41819}$ In one study using archival specimens of ovarian carcinoma a combination of flow cytometry and image analysis was shown to be the strongest prognostic indicator, with these two methods being complementary for the study of DNA ploidy abnormalities. ${ }^{20}$ These methods could be used to complement each other in future studies.

It has also clearly shown the superiority of the cytospin technique when compared with the use of $5 \mu \mathrm{m}$ sections for image analysis. The skewing of the DNA histogram referred to above is clearly seen in the comparison of the results from the cytospin and $5 \mu \mathrm{m}$ sections of the phaeochromocytomas. In all but three of the cases the DI of the cytospin was higher than the DI of the $5 \mu \mathrm{m}$ section, with this "leftshift" resulting in eight tumours which had tetraploid histograms in the cytospins being classified as aneuploid in the $5 \mu \mathrm{m}$ sections.

A comparison of image analysis and flow cytometry using the cytospin preparation of phaeochromocytomas was not performed because the results from the ovarian tumours had previously shown such a high degree of correlation between these methods.

The superiority of the cytospin technique was also shown by the difference in CVs between the methods-the average CV obtained in the cytospin preparations was $5.9 \%$, compared with $13.6 \%$ in the $5 \mu \mathrm{m}$ sections $(p<0.001)$. The low CVs found in this study agree with those previously reported using this technique. ${ }^{1721}$ The greater accuracy allowed the resolution of three aneuploid peaks with DIs around 1.2 which were included in the diploid peaks in the slide histograms.

The combination of the "left-shift" and the difference in the CVs shows that the cytospin technique is more accurate than $5 \mu \mathrm{m}$ sections in determining the DNA content of cells. In some of the $5 \mu \mathrm{m}$ sections the coefficient of variation for the tumours was so high and the shape of the histogram was such that the value obtained as the DI is almost meaningless.

This study also highlights some of the problems associated with the technique of image analysis and emphasises the importance of using internal controls to determine the diploid DI in image analysis.

There are a large number of factors which need to be rigorously controlled in the staining technique to ensure reliable results in image analysis. These have previously been reviewed, and include the hydrolysis time, the $\mathrm{pH}$, temperature, age of the Schiff reagent, the purity of the pararosaniline dye used, and the type of fixative. ${ }^{22}$ If these are not standardised they can also produce high CVs.

The $5 \mu \mathrm{m}$ sections and the cytospin preparations in this study were stained in four groups, and despite rigorous control of the staining technique a variation in the staining was noted between them. Although most of the diploid peaks occurred in the same position, there was a variation of almost fourfold between the lowest and the highest values of the diploid peak in absolute units.

This variability in staining has also been reported in the staining of archival specimens with fluorescent dyes for flow cytometry, and thus is presumably due to either the method of fixation or the age of the tissue block. ${ }^{1}$

The inaccuracy produced by this variability was corrected by measuring the DNA content of fibroblast nuclei in the same $5 \mu \mathrm{m}$ section or cytospin, and using this value as the diploid DI. The DNA content of the tumour was then compared with this value. The lymphocytes that were measured were often pyknotic and saturated the screen image of the cell, and this may also result in inaccuracies in the diploid DI. Thus fibroblasts, where the nuclear material was more dispersed as in the tumours, were preferred as the diploid control.

In conclusion, image analysis using the cytospin preparation can be used to analyse paraffin wax embedded tissue accurately, and correlates well with values obtained by flow cytometry. There are, however, several potential problems with image analysis of paraffin wax embedded tumours which must be recognised and avoided to permit accurate assessment of tumour ploidy.

This work was supported by a Sydney Tapping Beques Scholarship, Postgraduate Committee of Medicine, University of Sydney.

1 Hedley DW, Friedlander ML, Taylor IW, et al. Method for analysis of cellular DNA content of paraffin-embedded pathological material using flow cytometry. J Histochem Cytochem 1983;31:1333-5.

2 Kute TE, Muss HB, Hopkins M, et al. Relationship of flow cytometry results to clinical and steroid receptor status in human breast cancer. Breast Cancer Res Treat 1985;6: 113-21.

3 Friedlander ML, Hedley HW, Taylor IW, Russel P. Influence of cellular DNA content on survival in advanced Influence of cellular DNA content on survival

4 Yasnoff WA, Mayer DA, Mahran HE, et al. An image analysis system for quantitation of cellular DNA content: analysis system for quantitation of cellular DNA

5 Dressler LG, Seamer LC, Owens MA. DNA flow cytometry and prognostic factors in 1331 frozen breast cancer specimens. Cancer 1988;61:420-7.

6 Kokal W, Sheibani K, Terz J, et al. Tumor DNA content in the prognosis of colorectal carcinoma. JAMA 1986;255:3123-7.

7 Volm M, Mattern J, Sonke J, et al. DNA distribution of nonsmall cell lung carcinomas and its relationship to clinica behaviour. Cytometry 1985;6:348-56.

8 Friedlander ML, Hedley DW, Swanson C, Russell P. Prediction of long-term survival by flow cytometric analysis of cellular DNA content in patients with advanced ovarian cancer. J Clin Oncol 1988;6:282-90. 
9 Lindahl OD, Alm P, Ferno M, et al. Prognostic significance of flow cytometric DNA measurements in stage I-II endometrial carcinoma. Anticancer Res 1987;7:791-8.

10 Hrafnkelsson J, Stal O, Eneestrom S, et al. Cellular DNA pattern, $\mathrm{S}$-phase frequency and survival in papillary thyroid cancer. Acta Oncol 1988;27:329-33.

11 Kheir SM, Barnes SD, Vanroenn JH, et al. Prognostic significance of DNA aneuploidy in stage I cutaneous melanoma. Ann Surg 1988;207:455-61.

12 Hosaka Y, Rainwater LM, Grant CS, et al. Phaeochromocytoma: nuclear deoxyribonucleic acid patterns chromocytoma: nuclear deoxyribonucleic acid pattern

13 Vindelov LL, Christensen JJ, Jensen G, et al. Limits of detection of nuclear DNA abnormalities by flow cytometric DNA analysis. Cytometry 1983;3:332-9.

14 Berryman I, Sterrett G, Papadimitriou JM. Feulgen DNA cytophotometry in histologic sections of mammary neoplasms. Analyt Quant Cytol Histol 1984;6:19-23.

$15 \mathrm{Fu}$ YS, Hall TL. DNA ploidy measurements in tissue sections. Analyt Quant Cytol Histol 1985;7:90-5.

16 McCready RW, Papadimitriou JM. An analysis of DNA cytometry on tissue sections in a rat liver model. Analyt
Quant Cytol Histol 1983;5:117-23.

17 Mikuz G, Hofstaedter F, Delgado R. Extraction of cells from paraffin-embedded tissue sections for single-cell DNA cytophotometry. Analyt Ouant Cytol Histol 1985;7:343-6.

18 Oud PS, Hanselaar AGJM, Pahlplatz MMM, et al Image DNA-index (ploidy) analysis in cancer diagnosis. Applied Optics 1987;26:3349-55.

19 Cornelisse CJ, de Koning HR, Moolenaar AJ, et al. Image and flow cytometric analysis of DNA content in breast cancer. Analyt Quant Cytol Histol 1984;6:9-18.

20 Rodenburg CJ, Ploem-Zaaijer JJ, Cornelisse CJ, et al. Use of DNA image cytometry in addition to flow cytometry for the study of patients with advanced ovarian cancer. Cancer Res 1987;47:3938-41.

21 van Driel-Kulker AMJ, Mesker WE, van der Burg MJM Ploem JS. Preparation of cells from paraffin-embedded tissue for cytometry and cytomorphologic evaluation. Analyt Quant Cytol Histol 1987;9:225-31.

22 Mikel UV, Fishbein WN, Bahr GF. Some practical considerations in quantitative absorbance microspectrophotometry. Preparation techniques in DNA cytometry. Analyt Quant Cytol Histol 1985;7:107-18. 